\title{
Eksplorasi Nilai Pendidikan Lingkungan Cerpen Daring Republika: Kajian Ekokritik
}

\author{
Juanda Juanda \\ Fakultas Bahasa dan Sastra, Universitas Negeri Makassar, Makassar, 90234 \\ E-mail: juanda@unm.ac.id
}

Diterima: 26 September 2018

Direview: 05 Desember 2018

Diterbitkan: 31 Desember 2018

Hak Cipta @ 2018 oleh Penulis (dkk) dan Jurnal Sosial Humaniora (JSH)

*This work is licensed under the Creative

Commons Attribution International License (CC

BY 4.0).

http://creativecommons.org/licenses/by/4.0/

(c) (i) Open Access

\section{Subject Area : Language and Literature (Bahasa dan Sastra)}

\begin{abstract}
The purpose of this study is to explore the value of environmental education and interaction between characters and nature in the short stories of the Republika newspaper. This type of research is a qualitative study by describing descriptive or qualitative descriptive data. The data source comes from the Republika Newspaper which can be accessed in https: //lakonhidup.wordpress.com. The data focus on environmental phenomena in the short story of the 2015 to 2018 edition of Republika newspaper. The technique used is the content analysis technique. The data were analyzed using an ecocritical approach Grag Garrard (2004). Based on the results of the research, it was concluded that the republika short story contained an environmental theme whose proportions were very lacking. The dominant environmental phenomenon highlights natural and forest disasters. The value of Republika's short stories environmental education, namely: tree planting, reforestation of forests that have been exploited, the implementation of rules and regulations for deforestation, and animal conservation.
\end{abstract}

Keyword: Ecocriticism, Short Story, Republika Newspaper, forest exploitation

\section{Pendahuluan/Latar Belakang}

Pengarang karya sastra ada yang menjadikan alam sebagai representasi imajinasi mereka melalui cerpen. Hal ini merupakan cara pengarang menyerukan pemeliharaan lingkungan dengan cara berkomunikasi dengan pembaca karya sastra melalui media antara lain koran Republika. Pengarang yang berlatar belakang budaya dan etnis ada kalanya menonjolkan fenomena alam, budaya, dan etnis asal mereka. Setiap etnis memiliki cara khas dalam berkomunikasi (Juanda dan Azis, 2018: 71). Hal ini sering pembaca temukan dalam karya sastra yang bernuansa alam yang berkaitan dengan latar belakang pengarang, misalnya pengarang yang tinggal di Sumatra mengeksplorasi fenomena kabut asap, fenomena pantai yang abrasi. Pengarang asal Bali mengeksplorasi fenomena alam di Bali. Imajinasi pengarang yang dituangkan dalam cerpen yang bertemakan lingkungan terdapat dalam berbagai media di Indonesia, antara lain koran Republika versi daring yang bisa diakses secara daring oleh para pembacanya. Cerpen-cerpen ini perlu dikritik dengan berbagai pedekatan antara lain pendekatan sastra dan lingkungan yang dikenal dengan istilah pendekatan ekokritik.

Penelitian mengenai cerpen dengan kajian ekokritik telah dilakukan oleh berbagai ahli antara lain: Dwivedi Amitabh V; Karmakar, Shri Krishan Rai, Sanjukta Banerjee (2017); Kunhil and Zeenath Mohamed Kunhi, (2017); Ates (2017); Pattnaik and Itishri Sarangi (2017); Smith (2018); Marías C., Alcalde Peñalver E., Portela Lopa A. (2019). Namun, 
semua penelitian yang penulis telaah dari berbagai pakar tersebut belum ada yang menyoroti cerpen dalam media Republika dengan kajian ekokritik. Oleh karena itu, dalam penelitian ini peneliti memfokuskan pada eksplorasi fenomena nilai pendidikan lingkungan dalam cerpen Republika dengan menggunakan kajian ekokritik.

Salah satu dilema moral lingkungan yang kurang diperhatikan di negara dunia ketiga adalah asimilasi dialektis di antara antroposentrisme dan ekosentrisme. Di negara-negara dunia ketiga di Asia, situasi ini bahkan lebih buruk dan ekososialis terkemuka menunjukkan penggambaran yang digambarkan ini dengan berbagai cara karena hal itu menjadi kebutuhan mereka. Sementara itu dalam kasus sastra beberapa penyair terkemuka Inggris dan India memunculkan apotheosis dan cerebrasi mereka dalam tulisan. Penyair India di satu sisi menggambarkan sikap antroposentrik orang-orang asli dan secara bersamaan mereka menganggap sikap ekosentris. Pengarang buku yang hebat seperti Keki N. Daruwalla dan Shiv K.Kumar mengungkap dunia dengan akulturasi, pemandangan dan suasananya, kekecewaan, kebingungan yang terjadi dari cara hidup pemikiran modern. Jadi, dari sudut pandang ini, ekopuisi mereka menjadi arbitrer di antara antroposentrisme dan ekosentrisme. Mereka mengungkapkan cahaya kesadaran lingkungan bersama dengan pemberlakuan hubungan manusia dan non-manusia yang patriarkal. Bersamaan dengan itu komposisi mereka yang dapat diramaikan melebarkan wacana sosio-ekologis dan pembaca dapat memahami demografi, urbanisasi, modernisasi, dan pengembangan aktivisme lingkungan (Karmakar, Shri Krishan Rai, Sanjukta Banerjee, 2017:15).

Penelitian Kunhil and Zeenath Mohamed Kunhi (2017) mengenai pembacaan ekofeminist "The
God of Small Things" karya Arundhati Roy berfokus pada bagaimana novelis menggunakan berbagai teknik yang menandakan mode pemberontakan alam dalam hal teori kelompok yang diredam dan motif komunikasi back channel. Novelis memuja Alam untuk mengaburkan pasangan dialektik. Dualisme Cartesian diperluas ke dikotomi budaya/alam. Roy mencakup subaltern ras manusia yang tertindas, dominan citra wanita yang dipenjara disepelekan. Pada tingkat lain, penulis mengacu pada hewan dan tumbuhan yang membutuhkan suara yang menceritakan kisah alam atau naluri bawaan melalui medium manusia: bentuk permintaan maaf mengenai kisah manusia diceritakan melalui hewan. Hubungan simbiotik alam mengumpulkan kekuatan karena mereka didasari oleh Roy melalui relasi metafora dan metonimi yang menunjukkan prinsip-prinsip kedekatan. Naluri bertahan hidup pada karakter perempuan digambarkan melalui bahasa ekologi yang melambangkan eksplorasi batas-batas dalam pasangan dialektika budaya/alam.

Fenomena Hutan adalah salah satu novel fiksi ilmiah kontemporer yang berfokus pada kemungkinan hasil bencana dari sikap antroposentris manusia terhadap alam di masa depan. Orang-orang Athshean tampaknya telah membangun masa depan secara sempurna yang ingin dicapai oleh pecinta alam, tetapi dunia mimpi telah menghadapi mimpi buruk yang tak terduga ketika mereka bertemu Yumens "orang-orang yang datang dari bumi." Meskipun novel ini dikenal sebagai cara Ursula K. Le Guin bereaksi terhadap perang Vietnam melalui contoh serangan militer yang serakah, kejam menyerang orang-orang tak bersalah dari planet baru yang mereka temukan. Penelitian ini menganalisis karya dari perspektif ekokritis karena menunjukkan kontras antara Yumens yang telah mengubah dunia mereka menjadi gurun setelah 
bertahun-tahun mengonsumsi sumber daya alamnya dan orang-orang Athshean yang telah berhasil membangun keseimbangan antara budaya dan alam. Alih-alih belajar dari orang-orang yang damai ini yang telah membentuk sebuah komunitas tanpa mengganggu keseimbangan alam, orang-orang militer terus menebang pohon dan memperbudak penduduk asli seperti yang mereka lakukan di planet mereka sebelumnya. Untuk melindungi planet mereka, orangorang Athshean yang tidak pernah mengalami kekerasan sebelumnya seperti itu di kota-kota mereka yang diperintah oleh perempuan. Mereka memutuskan menyerang mereka di bawah pimpinan Selver, yang telah melarikan diri dari Yumens. Hutan mengilustrasikan apa yang mungkin kita hadapi di masa depan jika konsekuensi sosial dan ekologi dalam interaksi dengan alam tidak diperhatikan (Ateş, 2017: 205).

Tulisan-tulisan topik lingkungan memberikan dimensi baru pada revolusi hijau dan gerakan konservasi. Para ahli lingkungan telah menunjukkan kepedulian pertumbuhan populasi yang cepat, penggunaan sumber daya alam secara berlebihan, menebangi pohon, membangun industri, membakar hutan, membangun gedung dan bendungan serta dampaknya bagi manusia. Sastra yang memainkan peran penting dapat dibaca dari perspektif hubungan sifat manusia. Toni Morrison melalui tulisantulisannya percaya dalam melestarikan sejarah untuk memodifikasi masa sekarang, mengamankan masa depan. Novel Morrison, Sula and Beloved, menunjukkan berbagai persepsi hubungan manusiaalam ini dan hubungan mereka dengan alam yang mengarah pada sifat patuh pada kekuatan mereka untuk bertahan dari bencana dan kejahatan yang ditimbulkan oleh lingkungan sekitarnya. Alam tidak hanya berfungsi sebagai latar belakang bagi Sula dan
Kekasih Morrison, tetapi lebih seperti makhluk hidup yang bereaksi terhadap eksploitasi manusia. Karya Morrison mencerminkan literasi ekologis di kalangan pembaca. Novel-novel Toni Morrison berbicara tentang korban laki-laki terhadap alam, yang menimbukan berbagai bencana. Alam berfungsi sebagai citra dalam novel-novel Morrison. Alam dan perempuan sama-sama menjadi korban penindasan, prasangka, dan praktik ketidaksetaraan laki-laki. Intervensi eko-feminis yang disajikan dalam novel ini berusaha menuju perdamaian global guna menciptakan dunia yang harmonis. Tulisan ini menggambarkan dominasi eksploitasi paralel manusia atas tubuh perempuan. Meskipun sastra tidak melayani tujuan untuk mengatasi masalah buatan manusia tetapi tentu saja dapat menciptakan kesadaran kebijaksanaan ekologis untuk memahami lingkungan dengan cara yang lebih baik (Pattnaik and Itishri Sarangi, 2017:609).

Penelitian Smith (2018: 311) menyajikan analisis filosofis-eko-kritis cerpen Riana Scheepers "Katvoet" (2009). Dalam karya sebelumnya saya penulis menganalisis teks dengan mengacu pada kerangka fenomenologis. Namun, dalam pandangan saya, kisah itu menawarkan lebih banyak kemungkinan penafsiran. Secara khusus dieksplorasi dengan sukses dalam ekokritis. Smith menggambarkan Alaimo, Hekman, Bennett, Buell, Burton Christie, Garrard, Iovino, Love, Morton, Warren, serta beberapa akademisi terkemuka Afrika di bidang ekokritis, yaitu Susan Smith dan Susan Meyer. Dia menguraikan perbedaan antara kerangka ekokritik yang menginformasikan arus sebagai lawan studi fenomenologi sebelumnya. Tulisannya menggunakan kerangka kerja ini untuk menantang beberapa gagasan filosofis Barat yang mendasari pemikiran Barat, seperti: 1. gagasan bahwa rasionalitas adalah ciri 
utama dan kemampuan manusia yang membuat mereka berbeda dan lebih unggul dari hewan. ; 2 . konsepsi manusia sebagai makhluk rasional dengan kemampuan berpikir logis; 3. keyakinan dalam oposisi dasar biner, seperti pikiran dan tubuh, wanita dan pria, subjektivitas dan objektivitas, budaya dan alam, dan rasionalitas dan emosi; 4. keyakinan dalam perbedaan ontologis antara manusia dan hewan. Ekokritisisme dan berbagai manifestasinya dalam literatur dibahas lebih lanjut. Setelah itu analisis cerita pendek "Katvoet" disajikan sesuai dengan kerangka kerja konseptual di atas. Dalam cerita, asumsi-asumsi dasar yang melandasi ide-ide filosofis Barat dianalisis secara kritis sebagaimana mereka disajikan dalam cerita, untuk menentukan sampai sejauh mana ide-ide ini ditantang. Apa yang tampaknya penting yang timbul dari analisis ini adalah dasar oposisi biner, ideide filsafat tradisional Barat, konsep alam dan dasar pemikiran antroposentrik yang mendominasi sastra ditantang dalam kisah ini.

Selanjutnya penelitian yang bergendre lain memotivasi siswa membuat puisi berdasarkan media lagu. Menjelaskan berbagai aktivitas online dengan berbagai alat platform Moodle. Kegiatan-kegiatan ini dirancang untuk meningkatkan pemahaman siswa tentang genre puisi sehingga menimbulkan ketertarikan dalam menelaah dan menciptakan puisi yang bertemakan alam (Marías C., Alcalde Peñalver E., Portela Lopa A. (2019).

Menurut Buell (1985: 7-8) kriteria ekokritik, antara lain lingkungan selain manusia menunjukkan sejarah manusia yang diimplikasikan dengan alam. Ekokritik sastra merupakan studi hubungan antara sastra dan lingkungan fisik (Glotfelty, 1996: xix ). Sastra apokaliptik merupakan sastra bawah tanah, hiburan bagi yang teraniaya (Thompson 1997: 13-14). Secara umum, pastoral adalah sastra apa saja yang mendeskripsikan desa dengan mengontraskannya secara implisit dan eksplisit dengan kota (Gifford, 1999: 2).

Garrard (2004: 4) menyebutkan ekokritik dapat membantu menentukan, mengeksplorasi, dan menyelesaikan masalah ekologi. Ecocriticism atau Environmental criticism menunjukan tulisan-tulisan kritis yang mengeksplorasi hubungan antara sastra dan lingkungan fisik dan biologis, yang dilakukan dengan kesadaran akut kehancuran yang ditimbulkan oleh aktivitas manusia terhadap lingkungan. Ecocritics tidak berbagi satu perspektif atau prosedur teoritis; sebaliknya, keterlibatan mereka dengan literatur lingkungan mewujudkan berbagai sudut pandang dan metode analisis tradisional, pasca-struktural, dan postkolonial (Hojjat Mahdi B dan Daronkolae, Esmaeil N., 2013). Studi sastra ekokritisisme memberikan wawasan menarik tentang representasi tempat dan alam dalam teks sastra. Sõrmus, Julia Tofantšuk, Suliko Liiv, (2013:108) mengusulkan sikap ekokritis, berfokus pada aspek alam dalam karya penulis kontemporer Inggris dan Estonia, Graham Swift dan Andrus Kivirähk; minat khusus adalah representasi alam, interaksi alam-budaya, dan kemungkinan cara baru melihat dunia. Dia menantang gagasan-gagasan humanisme yang mapan dan mengarahkan perhatian pada isu-isu lingkungan, novel kontemporer menyoroti arah ekosentrik yang unik dalam sastra.

Ada hubungan erat antara ekokritisisme dan sastra. Ini adalah studi interdisipliner Ekologi dan Kritik Sastra yang tidak biasa sebagai kombinasi dari ilmu alam dan disiplin humanistik. Dengan analogi, ecocriticism berkaitan dengan hubungan antara sastra dan lingkungan atau bagaimana hubungan manusia dengan lingkungan fisiknya tercermin dalam sastra (Sahu, Geeta 2014). Ekokritisisme adalah studi 
tentang hubungan antara sastra dan lingkungan, yaitu segala sesuatu yang berkaitan dengan manusia dan elemen bukan manusia seperti bumi, air, perumahan, pertanian, gua, bukit, tanaman, pohon, lautan, musim, hewan, angin, arsitektur kuno, batu, tanah dll, dianggap potret galeri dalam ekokritisisme (Yeshpal and Sayar Singh Chopra, 2015:145). Alam dan sastra selalu berbagi hubungan yang erat seperti yang dibuktikan dalam karya-karya penyair dan penulis lain di segala zaman di hampir semua budaya di dunia. Ekokritisisme adalah studi interdisipliner ekologi dan kritik sastra yang tidak biasa sebagai kombinasi dari ilmu alam dan disiplin humanistik. Dengan analogi, ekokritisisme berkaitan dengan hubungan antara sastra dan lingkungan atau bagaimana hubungan manusia dengan lingkungan fisiknya tercermin dalam sastra (Shankar, G. 2017).

Selain praktik mimetiknya, sastra terlibat proses eksegesis sebagai dasar teori ekokritis dan isyarat bidang studi baru. Bidang baru ini disebut "humaniora lingkungan." Secara historis, meskipun teori ekokritis dan pragmatiknya telah menjadi perhatian baru-baru ini dalam keilmuan sastra, minat mimetis alam di dunia selalu menjadi fakta yang berulang sejak awal adanya sastra tulis. Sastra melalui representasi alamnya yang beragam memungkinkan kita membentuk dan memperluas rasa kita tentang lingkungan yang berkelanjutan. Selain itu, membuat masalah dan mendiskusikan isu-isu lingkungan, telah mendesak meninjau kembali nilai-nilai budaya dan asumsi alam dan pelestariannya. Oleh karena itu, studi sastra yang berhubungan dengan representasi lingkungan dalam teks dapat menjadi pelajaran dan meningkatkan kesadaran kita tentang dunia alam. Dalam hal ini, orang mungkin bertanya-tanya apakah, penggambaran Shakespeare tentang alam dan penggunaan pengaturan ekologi dan lanskapnya dalam beberapa dramanya dapat membentuk kesadaran lingkungan setelah membacanya. Oleh karena itu, artikel ini menguraikan bagaimana drama Shakespeare tertanam dengan implikasi ekologi dan subteks. Dalam hal ini, rujukan drama dalam penelitin ini adalah As You Like It, The Winter's Tale (Umunç, 2015: 265).

Jika dilihat dari segi lingkungan, kebudayaanlah yang mengubah lingkungan alam menjadi lingkungan manusia (man made environment). Kebudayaanlah yang mengubah lingkungan, apalagi kebudayaan modern dengan teknologi yang bergantung pada sumber daya alam. Lalu muncul sebuah pertanyaan, apakah dalam pembangunan lingkungan yang manusiawi, yaitu kebudayaan, manusia semakin menyempurnakan lingkungan atau justru merusaknya. Ekokritisisme sebagai model studi kritis melihat representasi alam dan lanskap dalam teks-teks budaya, dengan memperhatikan sikap terhadap 'alam' dan retorika yang digunakannya (Chakraborty, D. 2016).

Berfokus pada gelombang perkembangan ekokritisisme yang menganggap sastra fungsional serta keadaan darurat yang ditimbulkan oleh krisis lingkungan dan contoh kehampaan interior manusia modern di sisi lain, puisi modernis menyajikan pandangan hidup pada masyarakat modern, dan sering berkaitan dengan lanskap perkotaan sebagai salah satu faktor yang bertanggung jawab kepada generasi pada puisi-puisi awal T. S. Eliot yang menggambarkan kegelisahan spiritual yang ia identifikasi dalam masyarakat modern, meramalkan banyak analisis ekokritik (Antonielli, 2017: 296).

Melalui penceritaan kita dapat meningkatkan daya imajinasi, emosional, intelektual, rasa sosial, rasa etis, dan religius (Juanda, 2018:17). Pendidikan formal diharapkan memiliki sikap positif yang diwujudkan dalam bentuk perilaku yang religius, cekatan, 
terampil, dapat membedakan mana yang baik atau buruk, mana yang salah atau benar serta menghargai semua hal yang menjadi bagian kehidupan di alam (Juanda, 2010:9).

Masalah dalam penelitian ini adalah banyaknya cerpen yang bernuansa lingkungan dalam koran Republika namun pembaca kurang tersentuh dengan nilai-nilai pendidikan lingkungan yang direfleksikan oleh para pengarang dalam koran daring Republika tersebut. Tujuan penelitian ini adalah mengeksplorasi fenomena lingkungan dan nilai-nilai pendidikan lingkungan yang terdapat dalam cerpen-cerpen yang bertemakan lingkungan dalam Koran Republika versi daring.

\section{Metode Penelitian}

Jenis penelitian ini merupakan penelitian kualitatif dengan pemaparan data secara deskriptif atau kualitatif deskriptif. Sumber data berasal dari koran Republika yang dapat diakses secara daring dalam web https://lakonhidup.wordpress.com. Data penelitian ini adalah kata, frasa, klausa, dan kalimat yang berfokus pada fenomena lingkungan dalam cerpen koran Republika yang bertemakan lingkungan edisi tahun 2015 s.d. 2018. Teknik yang digunakan adalah teknik analisis isi. Ada tujuh cerpen yang dijadikan sumber data, yaitu: Shabrina "Langkah yang Gemetar", Republika 23 Agustus 2015; D Nilasyah "Derai dan Luruh", Republika 29 Januari 2017; Tjak S. Parlan "Pergi ke Bukit", Republika 4 Juni 2017; Zhizhi Siregar "Langit Tanpa Warna", Republika 4 Februari 2018; Zhizhi Siregar "Yang Terpenjara Waktu", Republika 25 Februari 2018; Risda Nur Widia "Obitarium Origami”, Republika 2 Septmber 2018; dan I Gede Aryantha Soethama "Ida Waluh Lereng Gunung Agung", Republika 26 November 2018. Analisis data; pada langkah ini data dianalisis dengan membaca keseluruhan cerpen dengan menggunakan pendekatan ekokritik Grag Garrard (2004): pencemaran, hutan, bencana alam, pemukiman, makhluk hidup, dan bumi.

\section{Hasil Penelitian dan Pembahasan}

Fenomena ligkungan yang terdapat dalam cerpen koran Republika adalah polusi, hutan, bencana, pemukiman, dan binatang. Fenomena dan pendidikan lingkungan dapat dilihat pada tabel 1. di bawah ini. 
Tabel 1. Fenomena dan Pendidikan Lingkungan Cerpen Republika

\begin{tabular}{|c|c|c|c|c|}
\hline No. & Judul Cerpen & Pengarang & Fenomena Lingkungan & Pendidikan Lingkungan \\
\hline 1 & $\begin{array}{l}\text { Langkah yang } \\
\text { Gemetar }\end{array}$ & Shabrina & $\begin{array}{l}\text { a. Pembalakan hutan } \\
\text { b. Penangkapan hewan- } \\
\text { hewan langka } \\
\text { c. Polusi air }\end{array}$ & $\begin{array}{l}\text { a. Menjaga kelestarian hutan } \\
\text { b. Pemeliharaan satwa langka } \\
\text { c. Membuang sampah pada } \\
\text { tempatnya }\end{array}$ \\
\hline 2 & Derai dan Luruh & D. Nilasyah & $\begin{array}{ll}\text { a. } & \text { Penebangan pohon bakau } \\
\text { b. } & \text { Bencana gempa dan } \\
\text { tsunami }\end{array}$ & $\begin{array}{l}\text { a. Pemeliharaan pohon bakau di } \\
\text { tepi pantai dan menjaga } \\
\text { keseimbangan ekosistem } \\
\text { b. Abrasi pantai }\end{array}$ \\
\hline 3 & Pergi ke Bukit & Tjak S. Parlan & $\begin{array}{ll}\text { a. } & \text { Pemukiman } \\
\text { b. } & \begin{array}{l}\text { Sebuah bukit digali } \\
\text { habis-habisan untuk } \\
\text { mendapatkan emas }\end{array} \\
\text { c. } & \begin{array}{l}\text { longsor akibat } \\
\text { penambangan }\end{array} \\
\end{array}$ & $\begin{array}{l}\text { a. Membuat lingkungaan tempat } \\
\text { tinggal tetap alami. } \\
\text { b. Memanfaatkan sumber daya } \\
\text { tidak merusak ekosistem. }\end{array}$ \\
\hline 4 & $\begin{array}{ll}\text { Langit } & \text { Tanpa } \\
\text { Warna } & \\
\end{array}$ & Zhizhi Siregar & Gempa bumi & Mitigasi bencana \\
\hline 5 & $\begin{array}{l}\text { Yang Terpenjara } \\
\text { Waktu }\end{array}$ & Zhizhi Siregar & $\begin{array}{ll}\text { a. } & \text { Penebangan hutan eboni } \\
\text { hitam } \\
\text { b. Pembalakan pohon di } \\
\text { hutan lindung }\end{array}$ & $\begin{array}{l}\text { a. Memelihara kelestarian hutan } \\
\text { b. Memelihara hewan }\end{array}$ \\
\hline 6 & $\begin{array}{l}\text { Obitarium } \\
\text { Origami }\end{array}$ & Risda Nur Widia & $\begin{array}{l}\text { Bencana alam: gempa bumi } \\
\text { dan tsunami }\end{array}$ & $\begin{array}{ll}\text { a. } & \text { Menghindari penambangan } \\
& \text { liar } \\
\text { b. Menjaga tumbuhan dengan } & \text { penanaman pohon (reboisasi). } \\
\text { c. merawat ekosistem laut. }\end{array}$ \\
\hline 7 & $\begin{array}{l}\text { Ida Waluh di } \\
\text { Lereng Gunung } \\
\text { Agung }\end{array}$ & $\begin{array}{l}\text { I Gede Aryantha } \\
\text { Soethama }\end{array}$ & $\begin{array}{l}\text { Bencana gempa bumi dan } \\
\text { letusan gunung }\end{array}$ & Pelestarian hutan di lereng gunung \\
\hline
\end{tabular}

Berdasarkan tabel di atas, fenomena lingkungan dan pendidikan lingkungan dalam cerpen Republika dapat diuraikan sebagai berikut:

Cerpen "Langkah yang Gemetar" menceritakan tokoh Khoz yang pernah menjadi polisi hutan 44 tahun lalu merupakan seorang pemerhati lingkungan, khususnya hutan. Khoz banyak melakukan usaha agar hutan bisa terlindungi dari serangan manusia serakah yang suka menebang hutan. Oleh karena itu, Khoz tidak begitu banyak orang yang menyukainya. Namun, karena ucapanucapan nasehatnya yang mampu membakar semangat masyarakat untuk menjaga hutan, akhirnya ia banyak juga yang disukai orang dengan kemampuan retorikanya.
Cerpen yang berjudul "Derai dan Luruh" menceritakan tentang kekecewaan tokoh Derai dan Luruh yang kecewa atas kondisi pantai yang sangat memprihatinkan. Pantai tersebut sudah dijadikan lahan komersial. Beberapa lama setelah proses urbanisasi di pantai tersebut, terjadi gempa yang kemudian disusul tsunami yang memporakporandakan setengah bagian kota. Akhirnya, setelah dua tahun pascagempa terjadi dibangun kembali bangunan-bangunan. Namun, kondisi kota di dekat pantai tersebut kondisinya makin ganas.

Cerpen "Pergi ke Bukit" menggambarkan perubahan yang terjadi pada suatu tempat. Rumahrumah sudah banyak dibangun tahun demi tahun. Namun, ada satu bukit yang menyimpan emas dan warga banyak yang mengeruti bukit tersebut. Hingga 
pada akhirnya terjadi tanah longsor dan memakan korban jiwa.

Dalam cerpen "Langit Tanpa Warna" dijelaskan bahwa manusia harus bersama-sama saling membantu untuk menghindari diri dari bencana gempa bumi. Cerpen tersebut juga menjelaskan bahwa tidak boleh ada perbedaan pendapat dalam hal penafsiran alam semesta.

Kondisi hutan dalam cerpen "Yang Terpenjara Waktu" digambarkan memprihatinkan. Hutan Eboni yang terdapat di Toraja digerus habis karena ditebang oleh orang-orang yang tidak bertanggung jawab. Akhirnya kehidupan flora dan fauna di hutan tersebut menjadi terganggu dan terancam habitatnya.

Obituarium Origami” Cerpen ini mengisahkan peristiwa gempa bumi dan tsunami yang menghancurkan kota kelahiran tokoh Aku dalam cerita. Peristiwa bencana tersebut yang menyebabkan kehilangan kedua orangtuanya. Melalui pesan origami, tokoh Aku mencurahkan segala kesedihannya. Pesan origami yang ditulisnya, penuh dengan untaian doa dan harapan. Bencana yang terjadi menyebabkan kematian dan mayat-mayat berbau bangkai bergelimpangan. Melalui kertas origami, ia berharap semoga kelak ia dapat dipertemukan dengan kedua orangtuanya. Ketujuh cerpen di atas memiliki lima fenomena lingkungan, yaitu: polusi, hutan, bencana, pemukiman, dan binatang.

\section{Polusi}

Polusi ditemukan dalam cerpen "Langkah yang Gemetar. Tokoh Khoz selalu menjaga sungai dari tumpukan sampah dan enceng gondok. Para penduduk seenaknya membuang sampah di sungai sehingga menjadikan encek gondok tumbuh subur. Akibatnya aliran air sungai terhalang. Contoh kutipan pada data (1) di bawah ini
(1) Hampir setiap waktu Khoz pergi menyusuri Sungai Grindulu. Mengumpulkan sampah, menanam bibit tanaman di pinggir sungai, membersihkan sampah, dan eceng gondok. Ia menegur warga jika kedapatan membuang sampah ke sungai (Shabrina, 2015).

\section{Hutan}

Persoalan hutan yang banyak ditemukan dalam cerpen Republika, yaitu pada cerpen Langkah yang Gemetar, Derai dan Luruh, Pergi ke Bukit, dan Yang Terpenjara Waktu. Penenebangan hutan dapat menyebabkan kerusakan pada alam dan merugikan manusia serta bisa mengakibatkan bencana alam. Hal ini terjadi menipisnya ozon (Mishra, S.K \& Sarangi, I. 2017). Contoh kutipan dalam data di bawah ini.

(2) Dulu tempat ini orang-orang membuat kelompok untuk penebang kayu lalu kayu dijual pada pengepul lalu di kirim ke daerah-daerah. Mereka kemudian merasa terganggu dengan selembaranselembaran aturan yang di berikan oleh $\mathrm{Khoz}$ (Shabrina, 2015).

(3) Tanaman bakau itu masih hidup setelah berumur puluhan tahun. Dan akarakarnya masih menjalar berkembangbiak terlihat dalam beningnya air laut. Namun sekarang sudah jauh tenggelam terendam kedelaman air laut (Nilasyah, 2017).

(4) Ladang-ladang yang dulu terbentang, kini sudah mulai terkikis dan dijadikan tambang emas. Dulu masyarakat menggantungkan hidupnya dengan berkebun (Parlan, 2017).

(5) Semakin kami menyusuri hutan, jejak-jejak manusia yang menebang pohon hutan semakin terlihat nyata. Dari tahun ke tahun bumi Sulawesi tak lagi ramah lingkungan. Limara, eboni hitam yang terkenal di dunia telah menutup mata banyak manusia untuk pelestarian (Siregar, 2018).

Permasalahan hutan di sini sangat mengganggu kelangsungan kehidupan ekosistem dan keseimbangan alam karena hutan dieksploitasi secara berlebihan. Dwivedi Amitabh V; Devi, Shri Mata Vaishno (2017) alam bilamana dieksploitasi berlebihan berdampak negative bagi manusia. Hutan mengilustrasikan apa yang mungkin kita hadapi di masa depan jika konsekuensi sosial dan ekologi dalam interaksi dengan alam tidak diperhatikan (Ateş,2017:205). 


\section{Bencana Alam}

Bencana alam banyak ditemukan dalam cerpen seperti cerpen Derai dan Luruh, Langit Tanpa Warna, Pergi Ke Bukit, Obitarium Origami, dan Idah Waluh Lereng Guning Agung. Data (6), (7), (8), (9) dan (10) di bawah ini

(6) Getaran gempa kali ini sangat kuat sehingga meruntuhkan hotel dan gendung-gedung di pusat kota. Dalam sekejap setelah pengumuman tsunami bangunan -bangunan tersebut hilang tergilas derasnya gelombang tsunami (Nilasyah,2017).

(7) Waktu itu kami sedang panen. Kita dapat menolong masyarakat Langit Kelabu ketika mereka dilanda musibah bencana gempa yang menelan jutaan nyawa, hanya dengan membuka pintu. Nanti saat jembatan sudah selesai bantuan akan segara dating dengan mudah jika terjadi bencana (Siregar, 2018).

(8) "Bersama dua penambang lainnya, Dali tertimbun tanah longsor saat sedang menggali lubang." (Parlan, 2017).

Peristiwa bencana alam terjadi pada analisis cerpen berikutnya yakni cerpen karya Risda Nur Widia berjudul "Obituarium Origami” tahun 2018.

Peristiwa Gempa bumi yang disusul dengan tsunami dahsyat telah meluluh-lantahkan tempat kelahiran tokoh Aku dalam cerita. Peristiwa bencana menyebabkan tokoh Aku kehilangan orangtua, sanak saudara dan teman-temannya. Ia menjadi seorang anak yatim, hidup sebatang kara yang tidak memiliki kejelasan masa depan. Bencana juga dapat menyebabkan goncangan secara psikologis pada korbannya, karena meninggalkan kesedihan yang begitu mendalam. Berikut dijelaskan dalam kutipan cerpen.

(9) Aku kehilangan kedua orangtuaku, teman dan kerabat-kerabatku hilang tak diketahui. Entah mereka ke dunia antah-berantah, tak diketahui. Tsunami dan gempa bumi itu juga melipat-lipat tanah di kampung halamanku. Aku sekarang tak memiliki siapapun atau apapun. Semua telah hilang ditelan nasib yang pahit (Widia, 2018).

Bencana alam dapat menimbulkan banyak korban seperti kematian massal, penyakit, dan gangguan psikis. Dalam cerita "Obituarium Origami”, pengarang menggambarkan secara jelas bagaimana mayat-mayat, bangkai dan potongan tubuh berserakan, menimbulkan bau busuk yang dapat menimbulkan macam penyakit usai peristiwa tsunami. Dengan peristiwa ini, hendaknya manusia berpikir agar lingkungan tetap dilestarikan. Melestarikan lingkungan dapat dimulai dengan hal sederhana, misalnya menjaga kebersihan laut, tidak merusak, penanaman pohon bakau.

Dalam cerpen menceritakan peristiwa bencana alam. Bencana tersebut berupa gempa bumi dahsyat dan ancaman gunung meletus disekitar pedesaan Kesimpar, lereng gunung Agung. Peristiwa mengerikan ini terjadi dalam kondisi larut malam, sehingga warga menjadi panik untuk segera mencari tempat perlindungan di area pengungsian. Kutipan yang menunjukkan peristiwa bencana dalam cerpen sebagai berikut.

(10) Tokoh Ananta menyusuri bukit-bukit Kahang dan pada saat itu terasa gempa dengan guncangan keras dan berkali-kali dengan waktu yang lama. Tokoh Ananta menyusuri desa data hingga memasuki desan Kesimpar guncangan semakin kerasss... tanah terbelah, pohon-pohon terhuyung, dan juga terdengar suara gemuruh seakan gunung Agung segera memuntahkan laharnya (Soethama, 2017).

Setiap peristiwa, seperti bencana alam dapat dijadikan pembelajaran bagi manusia agar tidak merusak alam, misalnya dengan menjaga hutan di lereng gunung atau dengan penghijauan. Fenomenafenomena tersebut dapat menjadi pengetahuan, bahwa betapa bencana alam sangat merugikan, bahkan dapat membunuh segala yang ada disekitarnya, termasuk manusia. Selain itu, gempa bumi juga dapat merusak bangunan-bangunan, misalnya dinding pura yang retak yang dilukiskan oleh pengarangnya. Tentu hal ini merugikan kita secara materil. Pura juga sebagai tempat suci, yakni tempat ibadah bagi umat beragama Hindu. Dengan kalimat lain, peristiwa bencana alam hendaknya agar manusia semakin dekat dengan pencipta alam. 
Bencana merupakan peringatan bagi jiwa yang memiliki akal. Banyak manusia yang sibuk dan lalai mengingat Tuhan, bahkan sibuk dengan maksiat. Jelas, hal ini juga memiliki korelasi dengan berbagai bencana di bumi. Tentang bencana alam telah dijelaskan dalam al-Qur'an surah Al-Hijr (15): 72-74 dan QS. Al-Dadiid (57): 22-24.

\section{Pemukiman}

Berbagai fenomena yang melanda pemukiman terutama di wilayah perkotaan dan kawasan pantai. Tingginya permukaan air laut dan gelombang besar menjadikan kota di pinggir pantai terancam tenggelam dan abrasi pantai. Data (11) dan (12) di bawah ini.

(11) Dengan saling berpandangan, Luruh dan Derai memikirkan Kota yang semakin sesak. permukaan laut yang sudah meninggi. Sekeliling pantai ini sudah dibeton tinggi, sisi pantai yang dulu terlihat, kini sudah tenggelam dan rata dengan air laut. Manusia kini bukan manusia kita yang dulu. Manusia sekarang seakan berburu sesuatu yang tidak jelas (Nilasyah, 2017).

(12) Sejak di bukanya lokasi penambangan, beberapa bangunan rumah design modern juga menjadi semakin banyak dibangun dalam waktu tiga tahun. Setiap bulan kendaraan-kendaran seperti sepeda motor dan mobil baru dibeli masyarakat yang bekerja sebagai penambang, seperti Herman Gendut yang sekarang sudah di panggil bos (Parlan, 2017).

\section{Binatang}

Cerpen Langkah yang Gemetar. Tokoh dalam cerpen ini melakukan perburuan satwa langka. Hal ini mereka lakukan untuk memenuhi kebutuhan hidupnya. Hal tersebut dapat dilihat pada kutipan berikut ini. Data (13), (14), (15), (16), dan (17).

(13) Penduduk mengadakan ronda malam membantu para hansip menghadang para guluk malam yang mengangkut kayu-kayu dari hutan. Khoz mendekati anak-anak yang gemar menangkap ayam hutan, burung, dan monyet- monyet yang merupakan satwa langka (Sabrina, 2015).

(14) Tertangkapnya Jaya, anak semata wayang mereka sebagai salah satu tersangka jaringan penjualan satwa langka, menjadi pukulan menyakitkan bagi mereka, impian kedua manula sirna (Sabrina,2015).

(15) Upaya yang dilakukan oleh Khoz dengan pendekatan pada anak-anak yang suka menangkap monyet hutan, ayam liar di hutan, dan burungburung. (Shabrina, 2015).

(16) Kini tidak ada kicauan burung-burung yang bersahutan (Siregar, 2018).

Selain menarasikan peristiwa bencana dalam cerpen karya Gde Aryantha Soethama berjudul "Ida Waluh di Lereng Gunung Agung" juga memberikan pemahaman pentingnya kelestarian pada hewan. Seperti yang tercantum pada kutipan berikut.

(17) Tidak ada satupun binatang, burung-burung, anjing, maupun sapi ternak semua sudah pindahkan di tempat pengungsian. Desa Kesimpar seakan menjadi tempat mati yang tak berpenghuni (Soethama, 2017).

Upaya menyelamatkan ternak saat evakuasi warga Desa Kesimpar kala peristiwa bencana sedang terjadi. Hal ini menunjukkan bahwa hewan merupakan bagian dari kehidupan manusia. Pelestarian hewan dapat dilakukan dengan sikap peduli. Hewan memerlukan perhatian manusia. dan telah menjadi fitrah bahwa hewan bertujuan untuk berkhidmat pada manusia. oleh karena itu, seyogyanya agar manusia memiliki sikap bijak bukan hanya sesama manusia tetapi juga makhluk lainnya di bumi. Masalah lingkungan menjadikan hilangnya keanekaragaman tumbuhan dan hewan (Ryan, John C. 2015). Hal senada juga disampaikan oleh (Kumar, 2017) perusakan alam menjadikan punahnya satwa liar.

\section{Interaksi Tokoh dengan Lingkungan}

Interaksi tokoh dengan lingkungan ditemukan dalam cerpen karya Shabrina, Nilasyah, Parlan, Siregar, Widia, dan Soethama. Ada empat jenis interakasi tokoh dengan lingkungan yaitu pelestarian lingkungan, pelestarian satwa langka, pemanfaatan lingkungan, dan mitigasi bencana. 


\section{Pelestarian lingkungan}

Tokoh Khoz dalam cerpen "Langkah yang Gemetar" melakukan pelestarian lingkungan terhadap perusakan yang dilakukan oleh masyarakat. Sikap tokoh mencerminkan sikap positif atau dinamis terhadap lingkungan dengan melalukan pelestarian. Begitu juga pada cerpen "Pergi ke Bukit". Namun, pada kelima cerpen selanjutnya sikap tokoh hanya statis terhadap lingkungannya yakni cerpen "Obtarium Origami" dan cerpen "Ida Waluh di Lereng Gunung Agung", "Langit tanpa Warna", "Yang Terpenjara Waktu", dan "Derai dan Luruh". Masing-masing sikap tokoh yang digambarkan oleh pengarang berisfat statis terhadap lingkungan dan hanya cenderung menggambarkan realitas kehidupan para tokoh tanpa upaya pelestarian lingkungan. Sikap tokoh Khoz dalam upaya pelestarian sungai tercermin melalui sikapnya. Berikut kutipan dalam cerpen.

(18) "Setiap hari Khoz pergi sungai mengambil sampah, eceng gondok, menanam pohon pinggir sungai dan melarang warga membuang sampah di sungai" (Shabrina, 2015).

Selain itu, ia juga memiliki sikap positif untuk melestarikan pohon dalam hutan. Berikut kutipan dalam cerpen.

(19) "Yang penting, kita mengganti dengan menanam 10 pohon dari satu pohon yang kita ambil," jelas Khoz (Shabrina, 2015).

Kutipan tersebut mendeskripsikan bahwa tokoh utama sangat memahami bahwa jika manusia memperlakukan alam dengan baik dan menjaga alam, maka alam akan membalas dengan memberikan hasil yang melimpah keoada manusia. Manusia dan alam bisa menjadi simbiosis mutualisme. Ekokritik sastra merupakan studi bagaimana memahami hubungan antara sastra dan lingkungan fisik (Glotfelty, 1996: xix).
Begitu pula tokoh dalam cerpen selanjutnya "Pergi ke Bukit". Tokoh Ibu Kayah bersama anaknya lebih memilih memelihara ladang yang dapat memenuhi kebutuhan sehari-hari meskipun kebunnya tidak cukup luas, dibandingkan pergi menambang emas di bukit yang dapat mengakibatkan bencana tanah longsor. Kutipan cerpen sebagai berikut.

(20) "Biar pun ladang tidak begitu luas, namun hati menjadi tenteram karena tetap bisa melestarikan dan merawat dengan membersihkan kebun warisan kakek (Parlan, 2017)."

\section{Pelestarian sastwa langka}

Ekokritisisme berkaitan dengan hubungan antara sastra dan lingkungan atau bagaimana hubungan manusia dengan memanfaatkan lingkungan fisiknya tercermin dalam sastra (Shankar, G. 2015).

(21) Upaya yang dilakukan oleh Khoz dengan pendekatan pada anak-anak yang suka menangkap monyet hutan, ayam liar di hutan, dan burungburung. (Shabrina, 2015).

Tokoh Khoz dalam cerpen "Langkah yang Gemetar" menyuarakan perlunya pelestarian sastwa langka. Ia sangat sedih dengan hewan-hewan yang hampir punah karena hutan yang dibabat habis. Berikut ditunjukkan dalam kutipan.

(22) "Mereka (ayam hutan, burung, dan monyet hutan) memiliki keluarga yang kalian tangkap. Bagaimana perasaan kalian jika bapak atau ibu kalian tidak kembali dari ladangnya?" Begitulah Khoz saat memberikan pemahaman terhadap anak-anak (Shabrina, 2015).

Selanjutnya dalam cerpen "Yang Terpenjara Waktu". Sikap tokoh Aku dalam melestarikan satwa hutan tercermin dalam kutipan saat ini ingin melaporkan pemburu binatang yang membawa senjata. Ia mengumpulkan bukti-bukti dengan memotret untuk kemudian ia laporkan. Berikut kutipan dalam cerpen. 
(23) "Ia melakukan potret sebanyak-banyaknya terhadap pembalakan hewan liar untuk dijadikan sebagai bukti laporan (Shabrina, 2015)."

Meskipun sastra tidak melayani tujuan untuk mengatasi masalah buatan manusia tetapi tentu saja dapat menciptakan kesadaran kebijaksanaan ekologis untuk memahami lingkungan dengan cara yang lebih baik (Pattnaik dan Itishri Sarangi, 2017: 609).

\section{Pemanfaatan lingkungan}

Alam merupakan sumber kehidupan bagi manusia. Pemanfaatan alam sebagai sarana manusia dalam berinteraksi dengan lingkungannya terdapat dalam cerpen "Derai dan Luruh". Pantai sebagai tempat rekreasi. Berikut kutipannya.

(24) "Sekeliling pantai sudah dibeton. Ini dapat dimanfaatkan oleh pengunjung jika ingin menyaksikan kecipak ombak" (Nilasyah, 2017).

Selanjutnya lingkungan dimanfaatkan sebagai makanan untuk memenuhi kebutuhan sehari-hari tokoh ibu Kayah dalam cerpen "Pergi ke Bukit". Berikut dalam kutipan. Suami ibu Kayah dulunya menggunakan dua ekor kerbau untuk membajak ladang. Ladang yang digarapnya sebagai sumber untuk memenuhi kebutuhan sehari-hari (Parlan, 2017). Selain itu, bukit yang dimanfaatkan oleh masyarakat sebagai sumber galian emas, namun tambang ini tidak dikelola dengan bijak sehingga menjadi sumber bencana. Seperti dalam kutipan berikut.

(25) "Dali bersama dua penambang lain tertimbun tanah longsor ketika sedang membuat lubang di bukit emas (Parlan, 2017).

(26) Hutan dan kayu yang diciptakan oleh Tuhan di muka bumi ini harus dipelihara. Bilamana kita menebang pohon untuk kebutuhan seperti pembangunan rumah maka harus menggatinya dengan penanaman pohon kembali sebab pohon, hutan merupakan sumber kehidupan, sumber air (Shabrina, 2015).

\section{Mitigasi bencana}

Fenomena bencana alam ditemukan dalam cerpen "Langit Tanpa Warna”. Tokoh Aku yang siap- siaga untuk membantu korban gempa bumi. Kutipan cerpen sebagai berikut.

(27) "Jika jembatan nanti sudah jadi, maka pertolongan akan mudah dilakukan untuk korban bencana gempa bumi "(Siregar, 2018).

Selanjutnya, cerpen karya Shabrina. Tokoh Khoz selalu membersihkan sampah dan eceng gondok dalam sungai, penanaman pohon pinggir sungai untuk mencegah terjadinya bencana banjir. Kutipan cerpen sebagai berikut.

(28) "Khoz yang mengayuh rakitnya sambil menelusuri sungai, ia mengambil sampah, eceng gondok, juga melarang warga membuang sampah sembarang. Selain itu, ia juga menanam pohon pinggir sungai (Shabrina, 2015).

\section{Pendidikan Lingkungan}

Ada berbagai jenis pendidikan lingkungan yang terdapat dalam cerpen Republika. Pembaca dapat memahami demografi, urbanisasi, modernisasi, dan pengembangan aktivisme lingkungan (Karmakar, Shri Krishan Rai, Sanjukta Banerjee, 2017:15). Sastra dianggap media seniman sastrawan dalam mendokumentasikan pengalaman mereka serta pengalaman orang lain dapat memiliki nilai edukasi (Odinye, 2018). Menjaga kelestarian hutan, penanaman pohon atau reboisasi, pemeliharaan satwa langka, membuang sampah pada tempatnya, memeliharaan pohon bakau di tepi pantai dan menjaga keseimbangan ekosistem menjaga abrasi pantai, membuat lingkungaan tempat tinggal tetap alami. memanfaatkan sumber daya tidak merusak ekosistem, mitigasi bencana, memelihara hewan, menghindari penambangan liar, merawat ekosistem laut, serta perlu adanya aturan dan regulasi yang ditetapkan sehingga penebangan hutan secara ilegal tidak terjadi lagi.

Selain itu, pelestarian satwa harus diproritaskan. Melalui penceritaan kita dapat meningkatkan daya imajinasi, emosional, intelektual, 
rasa sosial, rasa etis dan religius serta peka lingkungan (Juanda, 2018:17). Pendidikan formal diharapkan memiliki sikap positif yang diwujudkan dalam bentuk perilaku yang religius, cekatan, terampil, dapat membedakan mana yang baik atau buruk, mana yang salah atau benar, menghargai semua hal yang menjadi bagian kehidupan di alam (Juanda, 2010:9). Dalam interaksi para tokoh dengan lingkungan dalam cerpen memberikan pemahaman kepada pembaca mengenai keseimbangan alam agar bumi dan isinya lestari guna keberlanjutan hidup manusia. Pemanfaatan lingkungan untuk kehidupan sehari-hari menjadikan pengelolaan alam dilaksanakan secara seimbang. Kepedulian lingkungan dan masalah alam semesta berperan dalam kehidupan manusia (N. Anjan \& Sathoshkumar, C. 2017).

\section{Kesimpulan}

Berdasarkan hasil penelitian dapat disimpulkan bahwa cerpen Republika memuat tema lingkungan yang proporsinya sangat kurang. Hanya tujuh cerpen dalam periode tahun 2015 s.d. tahun 2018 yang bertema lingkungan. Fenomena lingkungan dominan menyoroti bencana alam dan hutan. Dalam interaksi para tokoh dengan lingkungan dalam cerpen memberikan pemahaman kepada pembaca mengenai keseimbangan alam agar bumi dan isinya lestari guna keberlanjutan hidup manusia. Pemanfatan lingkungan untuk kehidupan sehari-hari menjadikan pengelolaan alam dilaksanakan secara seimbang. Pendidikan lingkungan dalam cerpen Republika, yaitu: menjaga kelestarian hutan; penanaman pohon atau reboisasi; pemeliharaan satwa langka; membuang sampah pada tempatnya; pemeliharaan pohon bakau di tepi pantai dan menjaga keseimbangan ekosistem; menjaga abrasi pantai; membuat lingkungan tempat tinggal tetap alami; memanfaatkan sumber daya; tidak merusak ekosistem; mitigasi bencana; menghindari penambangan liar; serta perlu adanya aturan dan regulasi yang tegas sehingga penebangan hutan secara ilegal tidak terjadi lagi.

\section{Referensi}

Anjan, N \& Athoshkumar, C. (2017). Ecological Concern in Ruskin Bond's Short Stories. Annamalai University. http://E-Journal in English UGC Approved. Pdf.

Antonielli, A. (2017). "Paradigms of the Ecocritical Canon in T. S. Eliot's Early Poems". Le Simplegadi, XV (17), 295-305. DOI: 10.17456/SIMPLE-75

Ateş, K. (2017). “An Ecocritical Reading Of The Word For World Is Forest 'Dünyaya Orman Denir' Adli Romanin Çevreci Eleştiri Bağlaminda Bir İncelemesi”. The Journal of Academic Social Science Studies, JASSS, International Journal of Social Science, 63, 205-212. Doi: http://dx.doi.org/ 10.9761/ JAS SS7378

Buell, L. (1995). The Environmental Imagination. Cambridge: Harvard University Press.

Chakraborty, D. (2016). “An Ecocritical Appreciation of Selected Short Stories of Jhumur Pandey". Silchar: Assam University. http:// www.daathvoyagejournal.com.

Dwivedi, M \& Khanna, M. M. (2017). "Eco-criticism In The Writings Of Ruskin Bond. Raman University Kota, Bilaspur". Research Journal of English Language and Literature (RJELAL) A Peer Reviewed (Refereed) International Journal, 5 (2), 134-137.

Garrard, Greg. (2004). Ecocriticism. New York: 
Routledge.

Gifford, T. (1999). Pastoral. New York and London:

Routhledge.

Glothfelty, C \& H. Froom (eds.). (1996). The Ecocriticism Reader: Landmarks in Literary Ecology. London: University of Goergia Press.

Hojjat, Bakhtiari, Daronkolae, M \& Najar, E. (2013).

"By the Name of Nature but against Nature: An

Ecological Study of Joseph Conrad's Heart of

Darkness". English Literature: Kharazmi

University, IRI. http://www.aripd.org/jaa.

Juanda dan Azis. (2018). "Wacana Percakapan Etnis

Bugis Wajo Sulawesi Selatan Indonesia:

Pendekatan Etnografi Komunikasi”. JP-BSI,

Jurnal Pendidikan Bahasa dan Sastra

Indonesia, 3(2), 71-76.

Juanda, Juanda. (2010).’Peranan Pendidikan Formal

Dalam Proses Pembudayaan". Lentera

Pendidikan, Jurnal Keguruan dan Ilmu

Pendidikan, 13 (1), 1-15. DOI : 10.24252/

lp.2010.v13n1a1

Juanda, Juanda. (2018).”Revitalisasi Nilai Dalam

Dongeng Sebagai Wahana Pembentukan

Karakter Anak Usia Dini”. Jurnal Pustaka

Budaya, 5 (2),11-18.

Karmakar, Goutam, Rai, S.K \& Banerjee, S. (2017).

"The Dichotomy in between Ecocentrism \&

Anthropocentrism: An Ecocritical Rendering of

Two Indian English Poets”. International

Journal of Applied Linguistics \& English

Literature, 6 (3),15-23. Doi:10.7575/aiac.

ijalel.v.6n.3p. 15

Kumar, V.N. (2017). Environmental Issues in the Shorter Fiction of Ruskin Bond. SPSR.

Kunhi, Ukhaya, M \& Kunhi, Z.M. (2017). “An Ecocritical Perspective of Arundhati Roy's The God of Small Things". http://journals. sagepub.com/home/sgo. Diunduh 14 April 2018.

Kunhi1, R.M. \& Kunhi, Z.M. (2017). An Ecocritical Perspective of Arundhati Roy's The God of Small Things. SAGE, Vol.- No-, 1 -6. DOI: 10.1177/2158244017712767/journals.sagepub. com/home/sgo

Marías, C, Alcalde, P.E \& Portela, L.A. (2019). Teaching Poetry Through Songs in a Virtual Environment: From Students' Reluctance to Their Acquiescence. In: Carrió-Pastor M. (eds) Teaching Language and Teaching Literature in Virtual Environments. Springer, Singapore.

Mishra, S.K \& Sarangi, I. (2017). "Role of Literature in Environmental Awareness: An Ecocritical Study of Aranyak (of the Forest) by Bibhutibhushan Bandyopadhyay". KIIT University. http:// International_ Multidiscipli nary_ Research Journal.

Nilasyah, D. (2017). "Derai dan Luruh," Republika, 29 Januari 2017, dari https://lakonhidup.com

Odinye, Ifeoma Ezinne. (2018). "Social Consciousness: An Analysis of Ifeoma Okoye's The Fourth World". Interdisciplinary Journal of African \& Asian Studies, 1(4), 1-18.

Parlan, Tjak S. (2017). "Pergi ke Bukit," Republika, 04 Juni 2017, dari https://lakonhidup.com

Pattnaik, M \& Itishri S. (2017). “Toni Morrison's Beloved \& Sula: An Eco-Critical Study". Galaxy: International Multisciplinary Research Journal www.galaxyimrj.com, The Criterion: An International Journal in English, 8(2),609616. www.the-criterion.com

Ryan, J.C. (2015). "Outside the East Asian landscape: A Survey of Ecocritism in Thay Literary Studies". http://dx.doi.org/10.15242/ ICEHM.ED815. Diunduh tanggal 14 April 
2018.

Sahu, G. (2014). "Ecocriticism- Understanding The Relationship Between Literature And Environment In Indian English Novels". H.R College of Commerce and Economics. Mumbai, India. Htttp:// www.saiompublic cations. com. Shabrina. (2015). "Langkah yang Gemetar," Republika, 23 Agustus 2015, dari https://lakonhidup.com

Shankar, G. (2017). "Exploration of Eco critical perspective in Amitav Ghosh's Hungry Tide and kamala Markandaya's Nectar in a Sieve “. Rajiv Gandhi University of Knowledge Technologies, Basar, Telangana State India. http://www.ijellh.com.

Siregar, Zhizhi. (2018). "Langit Tanpa Warna," Republika, 04 Februari 2018, dari https://lakonhidup.com

Siregar, Zhizhi. (2018). "Yang Terpenjara Waktu," Republika, 25 Februari 2018, dari https://lakonhidup.com

Smith, C. (2018). “"n Ekokrities-Filosofiese Perspektief op Die Kortverhaal 'Katvoet' (Riana Scheepers): Die mens en die natuur An Ecocritical-philosophical perspective on the short story 'Katvoet' (Riana Scheepers): Humans and nature". Tydskrif vir Geesteswetenskappe, Jaargang, 58 (2), 310329. Doi.10.17159/2224-912/2018/v58n2a7

Sõrmus., Tofantšuk, J \& Liiv, S. (2013). "Ecocritical Considerations of Nature in Contemporary British and Estonian Literature". Interlitt Era Ria 2013, 18(1), 108-123. DOI: http://dx.doi.org/10.12697/IL.2013. 18.1.08

Thompson, D. (1997). The End of Time: Faith and Fear in the Shadow of the Millenium. London: Minerva.
Umunç, H. (2015). “The Green Shakespeare: An Ecocritical Reading Yeşil Shakespeare: Ekoeleştirel Bir”. EFD/JFL Edebiyat Fakültesi Dergisi/Journal of Faculty of Letters Cilt, 32 ( 2), 256-276.

Yeshpal \& Chopra, S.S. (2015). “An Ecocritical of Kalidasas Rtusamhara”. IJLLH, International of English Language, Literature and Humanities, 3(5), 145-153. 